See discussions, stats, and author profiles for this publication at: https://www.researchgate.net/publication/353902648

\title{
Small-Strain Shear Modulus of Calcareous Sand under Anisotropic Consolidation
}

Article in Canadian Geotechnical Journal · August 2021

CITATIONS

0

6 authors, including:

Jinquan Shi

Chongqing University

7 PUBLICATIONS 15 CITATIONS

SEE PROFILE

Jian Hu

Chongqing University

1 PUBLICATION O CITATIONS

SEE PROFILE
READS

47

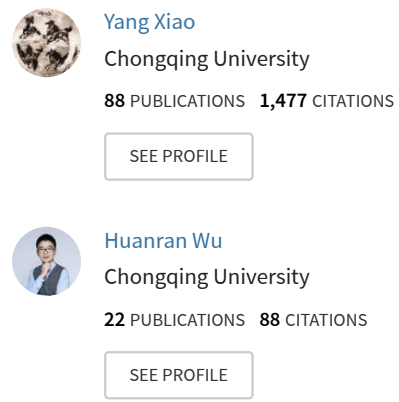

Some of the authors of this publication are also working on these related projects:

Constitutive model of soils under the multi-phase, multi-scale and multi-field coupling conditions View project

Stress-strain behavior and constitutive model of soils under the condition of the thermal-mechanical coupling View project 
1

2

3

4

5

6

7

8

9

10

11

12

13

14

15

16

17

18

19

20

\section{Small-Strain Shear Modulus of Calcareous Sand under Anisotropic Consolidation}

\section{Jinquan Shi}

School of Civil Engineering, Chongqing University, Chongqing, 400045, China.

Email: jinquan.shi@cqu.edu.cn

\section{Yang Xiao}

School of Civil Engineering, Chongqing University, Chongqing, 400045, China.

Email:xiaoy@cqu.edu.cn (Corresponding Author)

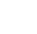

\section{Jian Hu}

School of Civil Engineering, Chongqing University, Chongqing, 400045, China.

\section{Email:20201601005z@cqu.edu.cn}

\section{Huanran Wu}

School of Civil Engineering, Chongqing University, Chongqing, 400045, China.

Email:hrwu@cqu.edu.cn

\section{Hanlong Liu}

School of Civil Engineering, Chongqing University, Chongqing, 400045, China.

Email: cehliu@cqu.edu.cn

\section{Wim Haegeman}

Department of Civil Engineering, Ghent University, Gent, 9000, Belgium. Email:

$$
\text { Haegeman.Wim@ugent.be }
$$


21 ABSTRACT: In this study, the small strain shear modulus of a calcareous sand was investigated by conducting bender element tests on both horizontal and vertical planes. The effects of sample preparation method, stress path and stress history on the developing of void ratio, the parameters in the modified Hardin Equation and the stiffness anisotropy were examined. The test results show that the moist tamping samples have the least void ratio variation among the five samples. The void ratio recovery in ${\sigma_{h}^{\prime}}_{h}=100 \mathrm{kPa}$ tests is higher than that in the $\sigma^{\prime}{ }_{v}=100 \mathrm{kPa}$ tests. The samples prepared in dry state have lower stiffness than those prepared in moisture state, which is not influenced by the anisotropic stress state. The stiffness anisotropy induced by the sample preparation method is significant under anisotropic consolidation. In $\sigma_{h}^{\prime}=100 \mathrm{kPa}$ tests, the stiffness ratios at the end of the unloading stage are lower than the initial values at the loading stage, which is not found in the $\sigma^{\prime}{ }_{v}=100 \mathrm{kPa}$ tests, meaning that the stress history and stress path could affect the stiffness anisotropy and cover the impact of fabric anisotropy.

KEYWORDS: small strain shear modulus, anisotropic consolidation, bender element, stiffness 
Small-strain shear modulus $G_{0}$ is an important mechanical parameter in geotechnical engineering, reflecting the deformation resistance of soil subjected to static and dynamic small amplitude shear loadings. The factors affecting the small-strain stiffness behavior of sandy soils can be summarized: physical properties, e.g., particle shape, size, fine content and gradation

(Wichtmann and Triantafyllidis, 2009; Carraro et al., 2009; Yang and Gu, 2013; Choo et al., 2015;

Wichtmann et al., 2015; Enomoto, 2016; Goudarzy et al., 2016; Payan et al., 2016; Liu et al., 2020;

Shi et al., 2020) and testing environment, e.g., saturation and temperature (Alramahi et al., 2010;

Khosravi et al., 2018; Rajabi and Sharifipour, 2018; Wang et al., 2019). The factors affecting soil

fabric and stress state such as sample preparation method, cementation, isotropic and anisotropic consolidation and over-consolidation, are also important for $G_{0}$ (Jardine, 1992; Fernandez and

Santamarina, 2001; Hoque and Tatsuoka, 2004; Sawangsuriya et al., 2006; Lee et al., 2009;

Clayton et al., 2010; Lee et al., 2011; Ng and Xu, 2012; Gu et al., 2013; Fioravante et al., 2013;

Montoya and DeJong., 2015; Senetakis and Li, 2017; Simatupang et al 2018; Payan and Chenari, 2019; Mendoza-Ulloa et al., 2020; Shi et al., 2021a; Liu et al., 2021; He et al., 2021). Some of the factors, for example, the overconsolidation ratio $O C R$, can be quantified and introduced into the

Hardin equation (Hardin and Black, 1966) to predict $G_{0}$ of sand, which is expressed as:

$$
G_{0}=\operatorname{Af}(e)\left(\frac{p^{\prime}}{p_{a}}\right)^{n} O C R^{m}
$$

where $A$ and $n$ are the experimentally determined constants; $f(e)$ is the void ratio function;

$O C R$ is defined as the ratio between the maximum effective stress in the loading stage and the effective stress in the unloading stage.

Calcareous sands are typical biogenic building materials and always own very high $\mathrm{CaCO}_{3}$ 
content (Wang et al., 2011; Van Impe et al., 2015; Giang et al., 2017; Xiao et al., 2017; Xiao et al.,

58

59

60

61

62

63

64

65

66

67

68

69

70

71

72

73

74

75

76

77 2019a; Liu et al., 2020). The mechanical properties of calcareous sand are always different with those of silica sands due to its special physical characteristics (Cassidy et al., 2002; Coop et al., 2004; Qadimi and Coop, 2007; Xiao et al., 2019b; Xiao et al., 2020; Xu et al., 2020; Tong et al., 2020; Tong et al., 2021; Xiao et al., 2021; Wu et al., 2021). Calcareous sands always exhibit higher irregularity in particle shape, which could promote the stiffness as the result of the stronger grain interlocking compared with that of silica sand at a similar state (Giang et al., 2017; Lv et al., 2019; Rui et al., 2020; Wei et al., 2020; Shi et al., 2021a). The small-strain shear modulus of calcareous sand was captured with the developing of offshore geotechnical engineering in marine areas where the infrastructure such as oil platform and artificial island are built upon the materials (Wang et al., 2011; Van Impe et al., 2015). Although the investigations on $G_{0}$ of calcareous sands have been performed during last decades, most of the attentions were paid on the isotropic stress state. Study disclosing the small-strain stiffness of calcareous sand under anisotropic consolidation is quite limited. It is generally recognized that the mechanical behavior of sands could be different under isotropic and anisotropic stress states, without excluding the small-strain stiffness (Hoque and Tatsuoka, 2004; Fioravante et al., 2013; Gu et al., 2013; Senetakis and Li, 2017; Payan and Chenari, 2019; He at al., 2021). For example, Fioravante (2000) performed multidirectional bender element tests on Kenya calcareous sands under both isotropic and anisotropic consolidation and showed that the small-strain shear modulus on horizontal plane is dominantly controlled by the horizontal effective stress and the stiffness on vertical planes can be conditioned with the variation of the ratio between horizontal and vertical effective stresses. In addition, stress history is an important parameter affecting the small-strain shear modulus of calcareous sands (Fioravante et al., 2013). It was proved that the interlocking among the calcareous grains could 
result in the uncompleted recover of soil fabric at the unloading stage, producing higher stiffness correspondingly (Shi et al., 2020). He et al. (2021) performed a series of multidirectional bender element tests on both calcareous and silica sands under anisotropic consolidation. They proposed that calcareous sands show significant differences in stiffness and stiffness anisotropy under anisotropic consolidation compared with silica sands. Until now, study revealing the unloaded stiffness behavior of calcareous sands under anisotropic stress state, especially disclosing the developing of stiffness anisotropy, is still limited. Especially considering the significant spatial dependent behavior of stiffness, the developing of stiffness anisotropy under anisotropic unloading stress path could be multifarious due to the various characteristics of soils having different origins.

The anisotropic small-strain stiffness, indicating the spatial differentiation of $G_{0}$ in soil matrix, can be determined by both laboratory and in situ testing techniques, for example bender element test and cross hole test respectively (Fiovarante et al., 1998; Youn et al., 2008; Ku and Mayne, 2013). In this study, a series of stress path controlled triaxial tests and multidirectional bender element tests were performed to evaluate the small-strain stiffness of a calcareous sand from Persian Gulf. The shear wave velocities can be measured on horizontal and vertical planes and expressed as $V_{H H}, V_{H V}$ and $V_{V H}$, corresponding to the small-strain shear modulus $G_{H H}$, $G_{H V}$ and $G_{V H}$ where the first and second subscripts denote the directions of shear wave propagating and particle motion respectively. The differences between $G_{H H}$ and $G_{H V}$ are always used for indicating the magnitude of stiffness anisotropy since both of them are measured on horizontal plane. Shi et al. (2021a) showed that the stiffness anisotropy of calcareous sands is highly depended on fabric anisotropy under isotropic stress state. However, the developing of stiffness anisotropy considering the effect of fabric anisotropy under anisotropic stress state is still 
unexplored.

\section{TESTING MATERIALS, APPARATUS AND PROGRAM}

\section{Testing Materials}

The calcareous sand, named S1 sand, is from an artificial island in Persian Gulf (Shi et al., 2021a). It is mainly composed of marine deposits like shell and coral. Based on the ASTM standard (ASTM International, 2014), the $\mathrm{CaCO}_{3}$ content of $\mathrm{S} 1$ sand was measured by using hydrochloric acid and can reach over $95 \%$. The physical properties of S1 sand are: specific gravity $G_{s}=2.81 ; C_{u}=3.89 ; D_{50}=0.602 \mathrm{~mm} ; e_{\max }=1.19 ; e_{\min }=0.73$. The particle size gradation and grain morphology of S1 sands are shown in Figure 1. As descripted in Shi et al. (2021a), the grain shape of S1 sand is angular and subangular, which was examined and quantified by X-ray CT scan tests and showed a sphericity value of 0.454 . The sphericity herein is defined as the ratio of the surface area of a sphere having the same yolume as a particle to the actual area of the particle (Shi et al., 2021a).

\section{Testing Apparatus}

All the tests were performed in a stress path control triaxial cell with the installation of three sets of bender elements. The bender elements were fabricated with the piezoelectric ceramics manufactured by Fuji Ceramics Corporation, Japan, having the size of $5 \mathrm{~mm}$ in width, $10 \mathrm{~mm}$ in length and $0.5 \mathrm{~mm}$ in thickness. The piezoelectric ceramics were coated with a layer of epoxy resin for isolation and protection. The wire diagram of the transmitting and receiving bender elements is series type. For measuring the shear wave velocity on horizontal planes, the frictional bender element technique was used (Fioravante, 2000). In this technique, bender element was glued on a small metal plate which was attached on the inner side of membrane through a hole. The metal plate has a similar curvature with the soil sample and a thickness of around $0.5 \mathrm{~mm}$. The travel 
time of the shear waves was determined with the distance between two metal plates. Apart from the bender element, the shear wave velocity measurement system also consists of a digital oscilloscope and a signal amplifier. In this study, a set of hall effect sensors were used for assisting the measurement of volume change. The diagram of the tested samples can be found in Figure 2 .

\section{Testing Program}

In this study, all the samples were prepared by the five methods detailed in Shi et al. (2021b) which are air and water pluviation (AP and WP), dry and moist tamping (DT and MT) and dry funnel deposition (DFD). Special attention should be given to the AP and DFD methods since they could be mixed up due to their different definitions in literatures. In the AP method, a specially designed pluviator, which is consisted of a sand holding funnel, five layer sieves and a sand collector, was used. The sample relative density is related to the mass flow rate of sands which is controlled by the funnel opening size. The DFD method was carried out by depositing sands by a long neck funnel with keeping the funnel opening near zero distance to sample surface. The densification was achieved by tapping the side of split mold. The initial relative densities of the samples were kept at $60 \pm 3 \%$. After saturation, samples were loaded and unloaded following the stress path plotted in Figure 3. The bender element tests were performed at the end of each loading stage which was kept at round 30 min for arriving at a stable fabric state. Bender elements were excited at a frequency of $15 \mathrm{kHz}$ and an amplitude of $20 \mathrm{~V}$. The peak-peak method was adopted for interpreting signals. The typical developing patterns of the transmitted and received signals are shown in Figure 4. It can be seen that with the variation of the effective stress, the travel time of the shear waves decreases firstly and increases again. In addition, the amplitude and the waveforms of the received signals seems not be affected by stress state. At the end of each test, the sands were collected and dried in an oven for checking the particle breakage. The test program 
is summarized in Table 1.

TEST RESULTS

\section{Developing of Void Ratio}

Firstly, it is necessary to mention that no significant particle breakage was found in all the

tests, which is consistent with the conclusion on the particle breakage of the same sand under

isotropic stress conditions in Shi et al. (2021a). They proposed that the insignificant breakage is attributed to the insufficient stress and well gradation of the calcareous sand.

Figure 5 (a) and Figure 5 (b) show the decrease and increase of the void ratio at the loading

and unloading stages of the two anisotropic consolidation tests respectively. All the void ratios are

normalized with the void ratio at the effective stress of $100 \mathrm{kPa}$ for the comparison of volume

change. For both of the tests, it is seen that the recovering of the void ratio at the unloading stage

is much lower than the volume change at the loading stage, meaning that the interlocking among

grains impedes the fabric recovery significantly. It is also found that the void ratio released at the

unloading stage in the tests of $\sigma_{h}^{\prime}=100 \mathrm{kPa}$ is higher than that in the test of $\sigma^{\prime}{ }_{v}=100 \mathrm{kPa}$.

Looking into the effect of sample preparation method, it is seen that the MT samples show the

least volume variation among the five samples, especially in the tests of $\sigma_{h}^{\prime}=100 \mathrm{kPa}$. It is also

noticed that the samples prepared in dry states, for example the AP, DT and DFD samples, show

larger volume changes than the samples prepared in moisture states like the MT and WP samples.

Shi et al. (2021a) concluded that sample made in dry state has a weaker grain interconnection, resulting in a lower soil stiffness, which can also be verified by the different soil deformation behavior given in this study. It is also known that the mean effective stress $p^{\prime}$ in the test of $\sigma_{v}^{\prime}$ $=100 \mathrm{kPa}$ is much higher than $p^{\prime}$ in the tests of $\sigma_{h}^{\prime}=100 \mathrm{kPa}$. However, the volume changes at the highest stress in the two tests show little differences, except the MT samples. It means that 
with the increase of the effective stress, the volume change becomes smaller and smaller. However, there is premise that particle breakage does not happen and original grains hold the sample structure. Once particles are broken at a certain stress level, the variation of void ratio could become complex and show a different pattern. The MT sample shows larger volume change in the $\sigma_{v}^{\prime}=100 \mathrm{kPa}$ test than in the $\sigma_{h}{ }_{h}=100 \mathrm{kPa}$ test, meaning the over-consolidated structure has the potential for further volume change at a higher stress level.

\section{Anisotropic Small-Strain Shear Modulus}

Figures 6 and 7 show the developing of $G_{0}$ of S1 sands under anisotropic consolidation. All the effect of void ratio, as expressed:

$$
f(e)=e^{-b}
$$

where $b$ is an experimentally determined constant. Shi et al. (2020) proposed that $b$ is 1.195 for the calcareous sand. Figure 6 shows the developing of $G_{H H}, G_{H V}$ and $G_{V H}$ with the effective vertical stress $\sigma^{\prime}{ }_{v}$. It is seen that $G_{H V}$ and $G_{V H}$ are increased with the increasing of $\sigma^{\prime}$. However, for $G_{H H}$, the increase of the effective stress seems having negligible effect on the developing of stiffness, meaning that the stiffness of the calcareous sand shows high spatial dependency on the direction of the effective stress. This characteristic of $G_{H H}$ keeps the same with the conclusion given by Fioravante et al. (2013) on Kenya carbonate sand. In addition, the cross-anisotropic stiffness behavior found in the isotropic consolidation tests (Shi et al., 2021a), represented by the equality between $G_{H V}$ and $G_{V H}$, is still valid in the anisotropic consolidation tests although the stiffness anisotropy indicated by the ratios between $G_{H H}$ and $G_{H V}$ could be lower than 1 due to the constant $G_{H H}$. In Figure $6(\mathrm{e})$, it is interesting to note that $G_{H V}$ is higher than $G_{V H}$ for the moist tamping samples. Shi et al. (2021a) indicated that the inequality between 
$G_{H V}$ and $G_{V H}$ of the moist tamping samples is resulted by the vertical tamping effort during the

196 sample reconstruction. It seems that this difference between $G_{H V}$ and $G_{V H}$ can not be

197 eliminated by the anisotropic consolidation stress path.

To further examine the stiffness variation with ${\sigma^{\prime}}_{h}$, the three modulus $G_{H H}, G_{H V}$ and $G_{V H}$ versus the normalized effective horizontal stress are plotted in Figure 7. It is seen that $G_{H H}$ shows a higher increasing rate than $G_{H V}$ and $G_{V H}$ with the increase of the effective horizontal stress, meaning that the stiffness increment on the horizontal plane is more contributed by horizontal stress. By combining the test results of $\sigma_{v}^{\prime}=100 \mathrm{kPa}$, it is concluded that $G_{H V}$ and $G_{V H}$ exhibit almost identical increase trends with the increase of horizontal and vertical stresses respectively, meaning that the stiffness on vertical planes shows negligible dependency on stress anisotropy for the calcareous sand.

Figure 6 and Figure 7 also show the stiffness of S1 sands at the unloading stage. As indicated by Fioravante et al. (2013), He et al. (2019), Shi et al. (2020) and He et al. (2021), $G_{0}$ of calcareous sands at unloading stage is apparently higher than that at the loading stage, which can be attributed to the strong interlocking among grains resulted by the irregular particle shape. In this study, the effects of sample preparation method and stress path on this stiffness behavior of 211 calcareous sand were examined. In Figure 6, it is found that $G_{H V}$ and $G_{V H}$ follow the general 212 trend that stiffness is higher at the unloading stage excluded the MT samples. It can be easily 213 understood that the unaffected $G_{H H}$ is due to the insensitivity of the horizontal stiffness to the 214 variation of the vertical stress, as He et al. (2021) proposed that the small strain stiffness is more 215 affected by the stress in the direction of wave propagation. For the MT samples, $G_{H H}, G_{H V}$ and $216 G_{V H}$ show almost constant stiffness values at the both loading and unloading stages. This special 217 stiffness behavior verifies the deduction in Shi et al (2021a) that the moist tamping samples of S1 
sands at around $60 \%$ relative densities exhibit an over-consolidated state due to the tamping effort

during the sample reconstruction, which is not changed by the anisotropic consolidation conducted in this study. calculating $G_{0}$ as:

$$
G_{0}=A f(e)\left(\frac{\sigma_{h}^{\prime}}{p_{a}}\right)^{\mathrm{n}_{\mathrm{h}}}\left(\frac{\sigma_{v}^{\prime}}{p_{a}}\right)^{\mathrm{n}_{\mathrm{v}}} O C R^{m}
$$

where $n_{h}$ and $n_{v}$ are the constants determined in anisotropic consolidation tests. The constant $m$ is determined by the regression on the relationship between the ratio of the normalized $G_{0}$ at unloading and loading stages and $O C R$, as detailed in Shi et al (2020). In this study, the constants, $A, n_{h}$ and $n_{v}$ are determined with the data of the loading stage in Figure 6 and Figure 7. The respective determination of $m$ for the two tests can be found in Figure 8 and Figure 9. Shi et al (2020) reported that the $m$ values of $G_{H H}, G_{H V}$ and $G_{V H}$ are almost identical for S1 sands under isotropic consolidation. From Figure 8, it seems that the effects of sample preparation and stress path on $m$ can not be neglected. To make a direct comparison on the values of theses parameters, $A, n_{h}, n_{v}$ and $m$ of all the tests are summarized in Table 2. It is seen that the samples prepared by the five methods show differences in $A$, behaving that the DFD samples and the MT samples have the lowest and the highest $A$ respectively. The MT samples also show the lowest $n_{h}$ and $n_{v}$ among five samples, indicating that they have the strongest fabric and are the least sensitive to the variation of the effective stress. For the parameter $m$, the consistency among $G_{H H}$, 
meaning that for these tests, the effect of loading history on $G_{0}$ is negligible.

He et al. (2021) found that $n_{h}$ and $n_{v}$ are not consistent for $G_{V H}$ and the differences are

242 larger for calcareous sands with more angular grains. However, in this study, this phenomenon

can not be unified for the samples prepared by different methods. He et al. (2021) also show the

different conclusions in literature about the values of $n_{h}$ and $n_{v}$ and they proposed that

differences could be due to the mineralogy and particle shape of sands. Looking into the test

results of this study, the effect of sample preparation method could not be neglectful.

\section{Stress-Induced Stiffness Anisotropy}

The ratio between $G_{H H}$ and $G_{H V}$ versus the effective vertical and horizontal stress is

plotted in Figure 10 (a) and (b) to indicate the developing of the stiffness anisotropy of the

calcareous sand in the loading and unloading processes. It is seen that the effect of sample

preparation method on stiffness anisotropy in isotropic consolidation tests (Shi et al. 2021a) is still

valid for the anisotropic consolidation tests. The AP and WP samples show the highest stiffness

anisotropy. The lowest stiffness anisotropy can be found in MT and DFD samples, which means

254 the order of fabric anisotropy induced by the sample preparation method is not changed by the

anisotropic stress state. The stress induced anisotropy is significant for all the tests, behaving as

the decreasing and the increasing of the stiffness ratios with the increase of the effective stress for $\sigma_{\mathrm{v}}^{\prime}=100 \mathrm{kPa}$ and $\sigma_{h}^{\prime}=100 \mathrm{kPa}$ tests respectively. For the stiffness anisotropy at the loading and unloading processes, differences are found between the two anisotropic consolidation tests. It is seen that the stiffness anisotropy at the loading and unloading stages is almost identical for the $\sigma_{\mathrm{v}}^{\prime}=100 \mathrm{kPa}$ tests. However, for the $\sigma_{h}^{\prime}=100 \mathrm{kPa}$ tests, the ratios between $G_{H H}$ and $G_{H V}$ at the end of the unloading stage are apparently lower than the initial stiffness ratios at the loading stage. This observation can be explained that for the $\sigma_{h}{ }_{h}=100 \mathrm{kPa}$ tests, the stress induced 
anisotropy is more significant than that in the $\sigma_{\mathrm{v}}^{\prime}=100 \mathrm{kPa}$ tests and the vertical loading results in higher stiffness on vertical planes. The mechanism is similar with that of the higher vertical stiffness found in MT samples. Li and Zeng (2014) reported that with the increase of the loading in the one-dimensional consolidation tests, the long axis of sand grains tends to be horizontal aligned and the fabric anisotropy can be enhanced. Following their findings, it is deduced that the decrease of the stiffness anisotropy in this study is not induced by the change of the soil fabric.

For the $\sigma_{\mathrm{v}}^{\prime}=100 \mathrm{kPa}$ tests, the equality of stiffness anisotropy at the loading and unloading stages indicates that stiffness is not affected with directionality. Also, the particle orientation and the fabric redistribution are deemed to be hardly affected by the variation of the horizontal loadings as well. It can be concluded that for the calcareous sands used in this study, the stiffness anisotropy

273 in the anisotropic consolidation test is more contributed by the stress history and stress path, which could cover the impact of fabric anisotropy. He et al. (2021) showed different stiffness anisotropy behavior of calcareous and silica sands subjected to anisotropic loading and unloading. They found that silica sand is hardly affected by the anisotropic loading history. However, for calcareous sand, the stiffness anisotropy can not recover to the initial state and is changed significantly at the end of the unloading stage. They deduced that particle shape is the primary factor inducing the different stiffness anisotropy behavior. Combined with the findings in this study, it is proposed that the couple effects between particle shape and stress path could lead the developing of stiffness anisotropy of the calcareous sands, which is worth to be investigated in further study.

\section{CONCLUSIONS}

This study investigates the anisotropic stiffness behavior of a calcareous sand from Persian methods as air and water pluviation, dry and moist tamping and dry funnel deposition in two 
anisotropic consolidation tests. The effects of sample preparation method and stress path on the developing of void ratio, the constants in Hardin equation and the stiffness anisotropy of the calcareous sands were examined. The main conclusions can be summarized as:

(1) The developing of void ratio is affected by the sample preparation method and stress path. Except the tests on MT samples, the $\sigma_{{ }_{\mathrm{v}}}=100 \mathrm{kPa}$ tests show similar void ratio variation with the $\sigma_{h}^{\prime}=100 \mathrm{kPa}$ tests at the highest stress state although it has a higher mean effective stress. The moist tamping samples subjected to loadings show the least volume variation among the samples prepared by the five methods. The void ratio released at the unloading stage in the tests of $\sigma^{\prime}{ }_{\mathrm{v}}$ $=100 \mathrm{kPa}$ is higher than that in the test of $\sigma_{h}^{\prime}=100 \mathrm{kPa}$.

(2) The small strain stiffness of the calcareous sand at the unloading stage is higher than that at the loading stage, which is proposed to be induced by the irregular particle shape. The increases of $G_{H H}$ are mainly contributed by the increase of horizontal effective stress. The overconsolidated state of moist tamping samples is not changed by the anisotropic consolidation stress state. The parameter $m$ in Hardin equation in anisotropic consolidation tests does not keep constant for $G_{H H}, G_{H V}$ and $G_{V H}$. The MT samples show the lowest values of $A, n_{h}$ and $n_{v}$ among the samples prepared by the five methods. The comparison between the values of $n_{h}$ and $n_{v}$ is also affected by sample preparation method.

(3) The stiffness anisotropy induced by the sample preparation methods is significant for the anisotropic consolidation tests. At the end of unloading stage in the $\sigma_{h}^{\prime}=100 \mathrm{kPa}$ tests, the stiffness anisotropy ratios are lower than the initial values at loading stage, which is not found in the $\sigma_{\mathrm{v}}^{\prime}=100 \mathrm{kPa}$ tests. For the calcareous sands used in this study, the stiffness anisotropy in the anisotropic consolidation tests is affected by the stress history and stress path more than the fabric redistribution. It is proposed that the couple effects between particle shape and stress path could 
lead the developing of stiffness anisotropy of the calcareous sands.

310

311

312

313

314

315

316

317

318

319

320

321

322

323

324

325

326

327

328

329

330

331

332

\section{DATA AVAILABILITY STATEMENT}

Some or all data, models, or code generated or used during the study are available from the corresponding author by request.

\section{DECLARATION OF INTERESTS}

The authors declare that they have no known competing financial interests or personal relationships that could have appeared to influence the work reported in this paper.

\section{ACKNOWLEDGEMENT}

The authors would like to thank the National Natural Science Foundation of China (Grant

Nos. 51922024, 41831282, and 52078085) and the Natural Science Foundation of Chongqing,

China (Grant No. cstc2019jcyjjqX0014). The tests were accomplished in the Laboratory of Geotechnics in Ghent University with the help of Filip Van Boxstael and Jan Van der Perre, which is greatly appreciated.

\section{REFERENCES}

ASTM International. D4373-14 Standard Test Method for Rapid Determination of Carbonate Content of Soils. West Conshohocken, PA; ASTM International, 2014.

Alramahi, B., Alshibli, K.A. and Fratta, D., 2010. Effect of fine particle migration on the smallstrain stiffness of unsaturated soils. Journal of Geotechnical and Geoenvironmental Engineering, 136(4), pp.620-628.

Carraro, J.A.H., Prezzi, M. and Salgado, R., 2009. Shear strength and stiffness of sands containing plastic or non-plastic fines. Journal of Geotechnical and Geoenvironmental Engineering, 135(9), pp.1167-1178.

Cassidy, M.J., Byrne, B.W. and Houlsby, G.T., 2002. Modelling the behaviour of circular footings under combined loading on loose carbonate sand. Géotechnique, 52(10), pp.705-712. 
333

334

335

336

337

338

339

340

341

342

343

344

345

346

347

348

349

350

351

352

353

354

355

356

357

Choo, H., Larrahondo, J. and Burns, S.E., 2015. Coating effects of nano-sized particles onto sand surfaces: Small strain stiffness and contact mode of iron oxide-coated sands. Journal of Geotechnical and Geoenvironmental Engineering, 141(1), pp.04014077.

Clayton, C.R.I., Priest, J.A. and Rees, E.V.L., 2010. The effects of hydrate cement on the stiffness of some sands. Géotechnique, 60(6), pp.435-445.

Coop, M.R., Sorensen, K.K., Bodas Freitas, T. and Georgoutsos, G., 2004. Particle breakage during shearing of a carbonate sand. Géotechnique, 54(3), pp.157-163.

Enomoto, T., 2016. Effects of grading and particle characteristics on small strain properties of granular materials. Soils and Foundations, 56(4), pp.745-750.

Fernandez, A.L. and Santamarina, J.C., 2001. Effect of cementation on the small-strain parameters of sands. Canadian Geotechnical Journal, 38(1), pp.191-199

Fioravante, V., Jamiolkowski, M., Presti, D.L., Manfredini, G. and Pedroni, S., 1998. Assessment of the coefficient of the earth pressure at rest from shear wave velocity measurements. Géotechnique, 48(5), pp.657-666.

Fioravante, V., 2000. Anisotropy of small strain stiffness of Ticino and Kenya sands from seismic wave propagation measured in triaxial testing. Soils and foundations, 40(4), pp.129-142.

Fioravante, V., Giretti, D. and Jamiolkowski, M., 2013. Small strain stiffness of carbonate Kenya Sand. Engineering Geology, 161, pp.65-80.

Giang, P.H.H., Van Impe, P.O., Van Impe, W.F., Menge, P. and Haegeman, W., 2017. Small-strain shear modulus of calcareous sand and its dependence on particle characteristics and gradation. Soil Dynamics and Earthquake Engineering, 100, pp.371-379.

Goudarzy, M., König, D. and Schanz, T., 2016. Small strain stiffness of granular materials containing fines. Soils and Foundations, 56(5), pp.756-764.

Gu, X., Yang, J. and Huang, M., 2013. DEM simulations of the small strain stiffness of granular soils: effect of stress ratio. Granular Matter, 15(3), pp.287-298. 
He, H., Li, S., Senetakis, K., Coop, M. R., and Liu, S., 2021. Influence of anisotropic stress path and stress history on stiffness of calcareous sands from Western Australia and the Philippines. Journal of Rock Mechanics and Geotechnical Engineering. https://doi.org/10.1016/j.jrmge.2021.03.015.

Hardin, B.O. and Black, W.L., 1966. Sand stiffness under various triaxial stresses. $J$ Soil Mech Found Div 1966; 92( SM2) , pp.27-42.

Hoque, E. and Tatsuoka, F., 2004. Effects of stress ratio on small-strain stiffness during triaxial shearing. Géotechnique, 54(7), pp.429-439.

Jafarian, Y., Javdanian, H. and Haddad, A., 2018. Dynamic properties of calcareous and siliceous sands under isotropic and anisotropic stress conditions. Soils and Foundations, 58(1), pp.172-184.

Jardine, R.J., 1992. Some observations on the kinematic nature of soil stiffness. Soils and Foundations, 32(2), pp.111-124.

Khosravi, A., Shahbazan, P. and Pak, A., 2018. Impact of hydraulic hysteresis on the small strain shear modulus of unsaturated sand. Soils and Foundations, 58(2), pp.344-354.

$\mathrm{Ku}, \mathrm{T}$. and Mayne, P.W., 2013. Evaluating the in situ lateral stress coefficient (K 0) of soils via paired shear wave velocity modes. Journal of Geotechnical and Geoenvironmental Engineering, 139(5), pp.775-787.

Lee, M.J., Choo, H., Kim, J. and Lee, W., 2011. Effect of artificial cementation on cone tip resistance and small strain shear modulus of sand. Bulletin of Engineering Geology and the Environment, 70(2), pp.193-201.

Lee, J., Kyung, D., Kim, B. and Prezzi, M., 2009. Estimation of the Small-Strain Stiffness of Clean and Silty Sands using Stress-Strain Curves and CPT Cone Resistance. Soils and Foundations, 49(4), pp.545-556.

Li, B. and Zeng, X., 2014. Effects of fabric anisotropy on elastic shear modulus of granular soils. Earthquake Engineering and Engineering Vibration, 13(2), pp.269-278. 
386

387

388

389

390

391

392

393

394

395

396

397

398

399

400

401

402

403

404

405

406

407

408

409

410

411

Liu, X., Zou, D., Liu, J., Zhou, C. and Zheng, B., 2020. Experimental study to evaluate the effect of particle size on the small strain shear modulus of coarse-grained soils. Measurement, 163, pp.107954.

Liu, X., Zhang, X., Kong, L., Li, X. and Wang, G., 2021. Effect of cementation on the small-strain stiffness of granite residual soil. Soils and Foundations, 61(2), pp.520-532.

Mendoza-Ulloa, J.A., Lombardi, D. and Ahmad, S.M., 2020. Small-strain stiffness degradation of artificially cemented sands. Géotechnique Letters, 10(2), pp.284-289.

Liu, H., Zhang, J.M., Zhang, X. and Wang, R., 2020. Seismic performance of block-type quay walls with liquefiable calcareous sand backfill. Soil Dynamics and Earthquake Engineering, 132, pp. 106092.

Lv, Y., Wang, Y. and Zuo, D., 2019. Effects of particle size on dynamic constitutive relation and energy absorption of calcareous sand. Powder Technology, 356, pp.21-30.

Nanda, S., Sivakumar, V., Donohue, S. and Graham, S., 2018. Small-strain behaviour and crushability of Ballyconnelly carbonate sand under monotonic and cyclic loading. Canadian Geotechnical Journal, 55(7), pp.979-987.

$\mathrm{Ng}, \mathrm{C} . \mathrm{W} . \mathrm{W}$. and $\mathrm{Xu}, \mathrm{J} ., 2012$. Effects of current suction ratio and recent suction history on smallstrain behaviour of an unsaturated soil. Canadian Geotechnical Journal, 49(2), pp.226-243.

Payan, M., Khoshghalb, A., Senetakis, K. and Khalili, N., 2016. Small-strain stiffness of sand subjected to stress anisotropy. Soil Dynamics and Earthquake Engineering, 88, pp.143-151.

Payan, M. and Chenari, R.J., 2019. Small strain shear modulus of anisotropically loaded sands. Soil Dynamics and Earthquake Engineering, 125, pp.105726.

Qadimi, A. and Coop, M.R., 2007. The undrained cyclic behaviour of a carbonate sand. Géotechnique, 57(9), pp.739-750.

Rajabi, H. and Sharifipour, M., 2018. Influence of weathering process on small-strain shear modulus $\left(\mathrm{G}_{\max }\right)$ of hydrocarbon-contaminated sand. Soil Dynamics and Earthquake Engineering, 107, pp.129-140. 
Rui, S., Guo, Z., Si, T. and Li, Y., 2020. Effect of particle shape on the liquefaction resistance of calcareous sands. Soil Dynamics and Earthquake Engineering, 137, pp.106302.

Sawangsuriya, A., Bosscher, P.J. and Edil, T.B., 2006. Application of soil stiffness gauge in assessing small-strain stiffness of sand with different fabrics and densities. Geotechnical Testing Journal, 29(3), pp.207-216.

Senetakis, K. and Li, H., 2017. Influence of stress anisotropy on small-strain stiffness of reinforced sand with polypropylene fibres. Soils and Foundations, 57(6), pp.1076-1082.

Shi, J., Haegeman, W. and Cnudde, V., 2021a. Anisotropic small-strain stiffness of calcareous sand affected by sample preparation, particle characteristic and gradation. Géotechnique, 71(4), pp.305-319.

Shi, J., Haegeman, W., Mascini, A. and Cnudde, V., 2021b. X-ray analysis on the effect of sample preparation on the microstructure of calcareous sands. Marine Georesources \& Geotechnology, 39(3), pp.302-311.

Shi, J., Haegeman, W. and Xu, T., 2020. Effect of non-plastic fines on the anisotropic small strain stiffness of a calcareous sand. Soil Dynamics and Earthquake Engineering, 139, pp.106381.

Simatupang, M., Okamura, M., Hayashi, K. and Yasuhara, H., 2018. Small-strain shear modulus and liquefaction resistance of sand with carbonate precipitation. Soil Dynamics and Earthquake Engineering, 115, pp.710-718.

Tong, C. X., Burton, G. J., Zhang, S., \& Sheng, D., 2020. Particle breakage of uniformly graded carbonate sands in dry/wet condition subjected to compression/shear tests. Acta Geotechnica, 15: 2379-2394.

Tong, C. X., Zhai, M. Y., Li, H. C., Zhang, S., \& Sheng, D., 2021. Particle breakage of granular soils: changing critical state line and constitutive modelling. Acta Geotechnica. DOI: $10.1007 / \mathrm{s} 11440-021-01231-8$

Van Impe, P.O., Van Impe, W.F., Manzotti, A., Mengé, P., Van den Broeck, M. and Vinck, K., 2015. Compaction control and related stress-strain behaviour of off-shore land reclamations with calcareous sands. Soils and Foundations, 55(6), pp.1474-1486. 
439

440

441

442

443

444

445

446

447

448

449

450

451

452

453

454

455

456

457

458

459

460

461

462

463

Wang, X.Z., Jiao, Y.Y., Wang, R., Hu, M.J., Meng, Q.S. and Tan, F.Y., 2011. Engineering characteristics of the calcareous sand in Nansha Islands, South China Sea. Engineering Geology, 120(1-4), pp.40-47.

Wang, J., Zhang, F. and Yang, Z.J., 2019. Anisotropy in small-strain shear modulus of permafrost at rising temperatures. Cold Regions Science and Technology, 160, pp.1-12.

Wichtmann, T. and Triantafyllidis, T., 2009. Influence of the grain-size distribution curve of quartz sand on the small strain shear modulus $\mathrm{G}_{\max }$. Journal of Geotechnical and Geoenvironmental Engineering, 135(10), pp.1404-1418.

Wichtmann, T., Hernández, M.N. and Triantafyllidis, T., 2015. On the influence of a non-cohesive fines content on small strain stiffness, modulus degradation and damping of quartz sand. Soil Dynamics and Earthquake Engineering, 69, pp.103-114.

Wu, Y., Li, N., Wang, X., Cui, J., Chen, Y., Wu, Y. and Yamamoto, H., 2021. Experimental investigation on mechanical behavior and particle crushing of calcareous sand retrieved from South China Sea. Engineering Geology, 280, pp.105932.

Xiao, Y., Wang, C., Zhang, Z., Liu, H. and Yin, Z.Y., 2021. Constitutive Modeling for Two Sands under High Pressure. International Journal of Geomechanics, 21(5), p.04021042.

Xiao, Y., Yuan, Z., Chu, J., Liu, H., Huang, J., Luo, S.N., Wang, S. and Lin, J., 2019a. Particle breakage and energy dissipation of carbonate sands under quasi-static and dynamic compression. Acta Geotechnica, 14(6), pp.1741-1755.

Xiao, Y., Liu, H., Chen, Q., Ma, Q., Xiang, Y. and Zheng, Y., 2017. Particle breakage and deformation of carbonate sands with wide range of densities during compression loading process. Acta Geotechnica, 12(5), pp.1177-1184.

Xiao, Y., Wang, L., Jiang, X., Evans, T.M., Stuedlein, A.W. and Liu, H., 2019b. Acoustic emission and force drop in grain crushing of carbonate sands. Journal of Geotechnical and Geoenvironmental Engineering, 145(9), pp.04019057.

Xiao, Y., Yuan, Z., Desai, C.S., Zaman, M., Ma, Q., Chen, Q. and Liu, H., 2020. Effects of load International Journal of Geomechanics, 20(7), pp.06020014. 
467 Xu, D.S., Huang, M. and Zhou, Y., 2020. One-dimensional compression behavior of calcareous 468 sand and marine clay mixtures. International Journal of Geomechanics, 20(9), p.04020137.

469 Yang, J. and Gu, X.Q., 2013. Shear stiffness of granular material at small strains: does it depend 470 on grain size?. Géotechnique, 63(2), pp.165-179.

471 Youn, J.U., Choo, Y.W. and Kim, D.S., 2008. Measurement of small-strain shear modulus G max $_{\text {of }}$ 472 dry and saturated sands by bender element, resonant column, and torsional shear tests. 473 Canadian Geotechnical Journal, 45(10), pp.1426-1438. 
Table 1. Test program using different sample preparation methods

\begin{tabular}{llcc}
\hline Tests & Sample preparation method & Initial relative density & Initial void ratio \\
\hline \multirow{2}{*}{ Air pluviation } & $57 \%$ & 0.908 \\
& Water pluviation & $61 \%$ & 0.892 \\
$\sigma_{h}^{\prime}=100 \mathrm{kPa}$ & Dry tamping & $57 \%$ & 0.905 \\
& Dry funnel deposition & $62 \%$ & 0.885 \\
& Moist tamping & $62 \%$ & 0.895 \\
\hline & Air pluviation & $62 \%$ & 0.883 \\
& Water pluviation & $60 \%$ & 0.904 \\
& Dry tamping & $60 \%$ & 0.894 \\
& Dry funnel deposition & $62 \%$ & 0.882 \\
& Moist tamping & $58 \%$ & 0.912 \\
\hline
\end{tabular}


Table 2. Summary of parameters in Equation (3).

\begin{tabular}{|c|c|c|c|c|c|c|c|}
\hline Tests & Parameters & $G_{0}$ & $\begin{array}{l}\text { Air } \\
\text { pluviation }\end{array}$ & $\begin{array}{c}\text { Water } \\
\text { pluviation }\end{array}$ & $\begin{array}{c}\text { Dry } \\
\text { tamping }\end{array}$ & $\begin{array}{l}\text { Dry funnel } \\
\text { deposition }\end{array}$ & $\begin{array}{c}\text { Moist } \\
\text { tamping }\end{array}$ \\
\hline \multirow{9}{*}{$\begin{array}{c}\sigma_{h}^{\prime}= \\
100 \mathrm{kPa}\end{array}$} & \multirow{3}{*}{$A$} & $\mathrm{HH}$ & 120.38 & 121.99 & 97.49 & 88.78 & 127.14 \\
\hline & & $\mathrm{HV}$ & 64.74 & 74.05 & 76.13 & 70.98 & 112.25 \\
\hline & & VH & 63.50 & 75.95 & 72.43 & 71.12 & 95.52 \\
\hline & \multirow{3}{*}{$n_{v}$} & $\mathrm{HH}$ & -0.032 & 0.081 & 0.102 & 0.049 & 0.004 \\
\hline & & HV & 0.340 & 0.339 & & & 0.302 \\
\hline & & VH & 0.350 & & & 0.332 & 0.220 \\
\hline & \multirow{3}{*}{$m$} & $\mathrm{HH}$ & -0.031 & -0.068 & 0.026 & -0.068 & -0.026 \\
\hline & & HV & 0.168 & & 0.174 & 0.179 & 0.025 \\
\hline & & VH & 0.162 & 0.156 & 0.183 & 0.156 & 0.015 \\
\hline \multirow{9}{*}{$\begin{array}{c}\sigma_{\mathrm{v}}^{\prime}= \\
100 \mathrm{kPa}\end{array}$} & \multirow{6}{*}{$n_{h}$} & $\mathrm{HH}$ & & 123.55 & 97.96 & 87.39 & 125.58 \\
\hline & & & 67.70 & 78.88 & 77.66 & 76.90 & 113.25 \\
\hline & & & 71.35 & 73.26 & 76.12 & 74.74 & 101.03 \\
\hline & & $\mathrm{HH}$ & 0.569 & 0.562 & 0.582 & 0.603 & 0.391 \\
\hline & & $\mathrm{HV}$ & 0.355 & 0.328 & 0.369 & 0.330 & 0.213 \\
\hline & & VH & 0.365 & 0.329 & 0.354 & 0.326 & 0.203 \\
\hline & \multirow{3}{*}{$m$} & $\mathrm{HH}$ & 0.197 & 0.176 & 0.171 & 0.211 & 0.001 \\
\hline & & HV & 0.188 & 0.166 & 0.177 & 0.209 & 0.001 \\
\hline & & VH & 0.187 & 0.179 & 0.161 & 0.192 & -0.025 \\
\hline
\end{tabular}



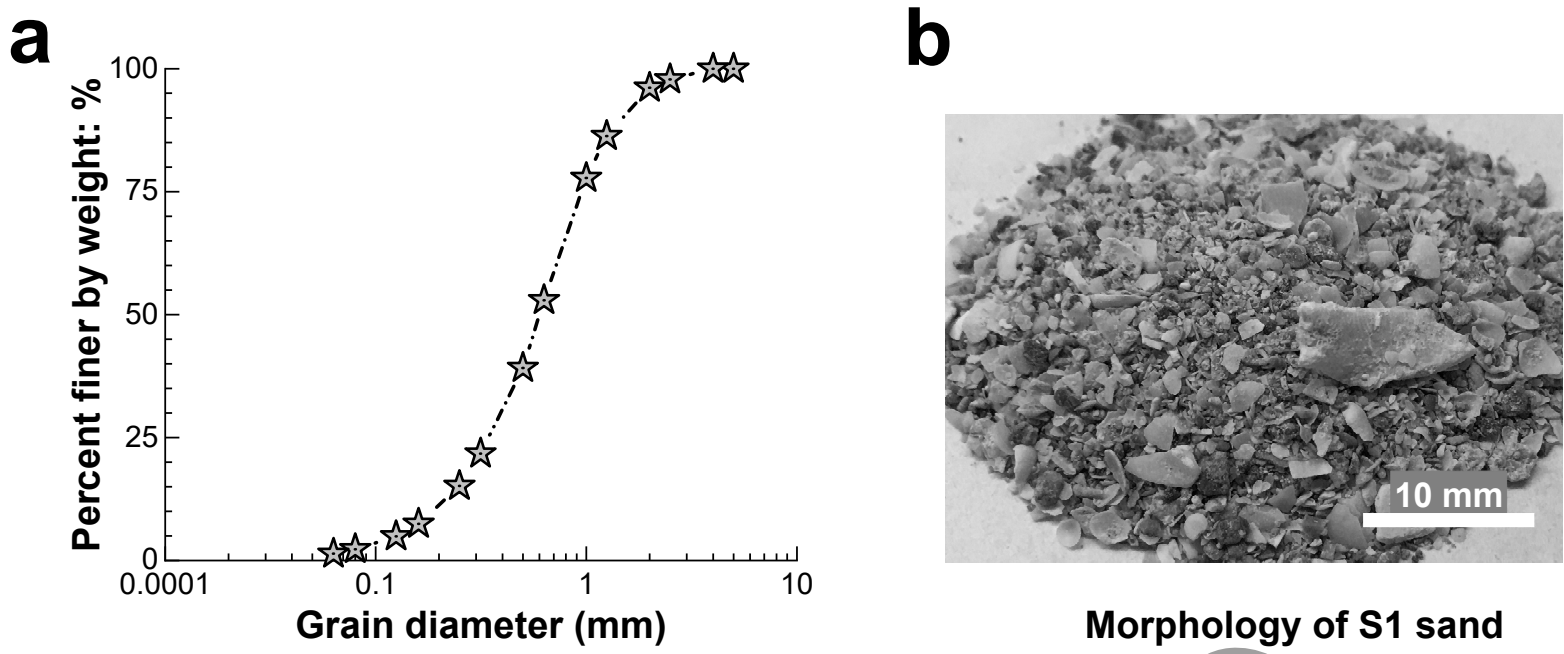

Morphology of S1 sand

Figure 1. Particle size gradation and morphology 


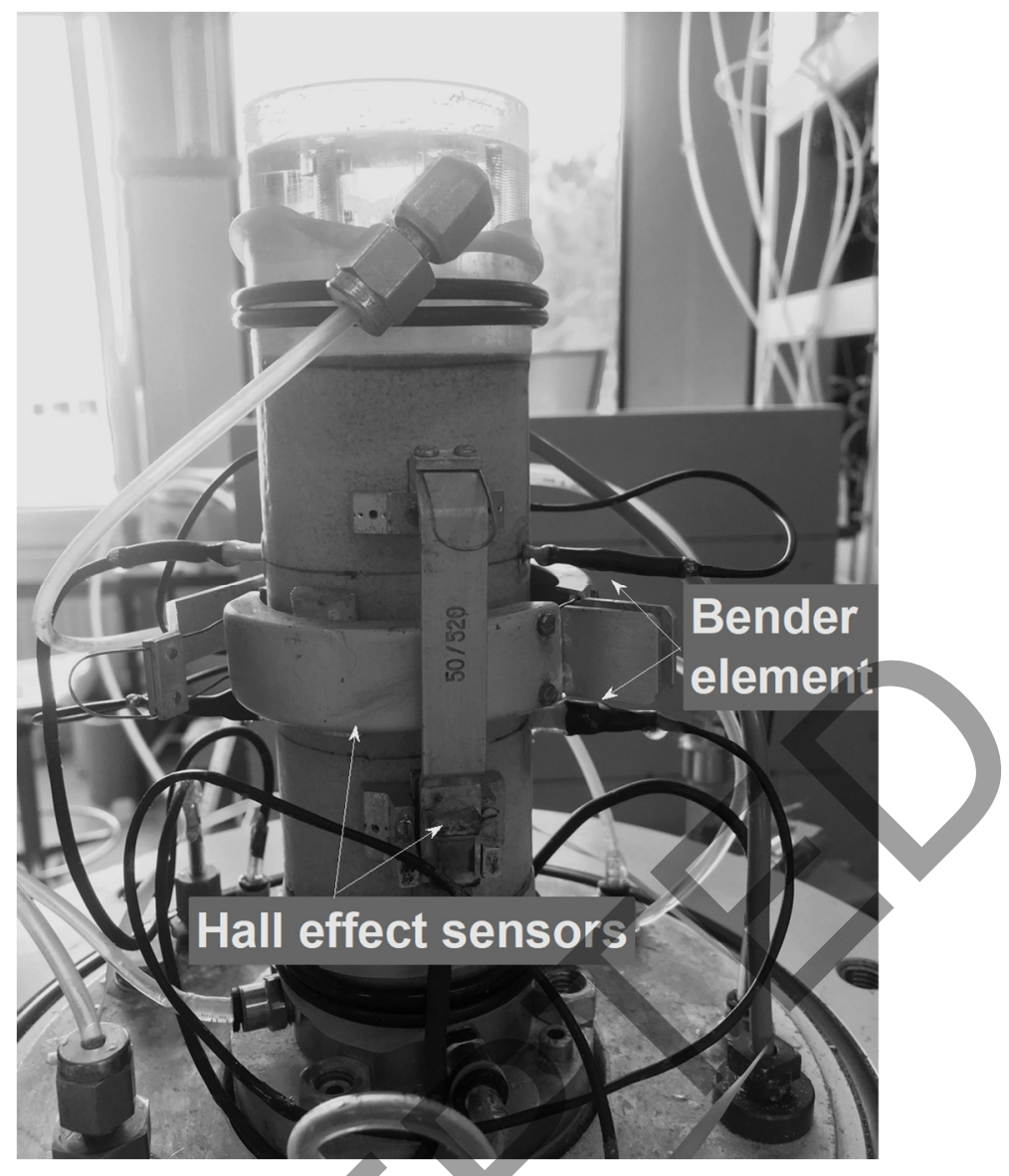

Figure 2. Diagram of the tested sample with bender elements and hall effect sensors

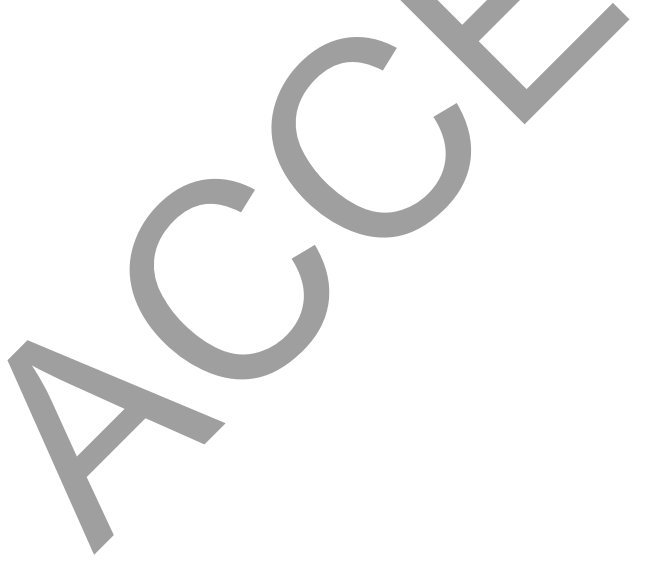



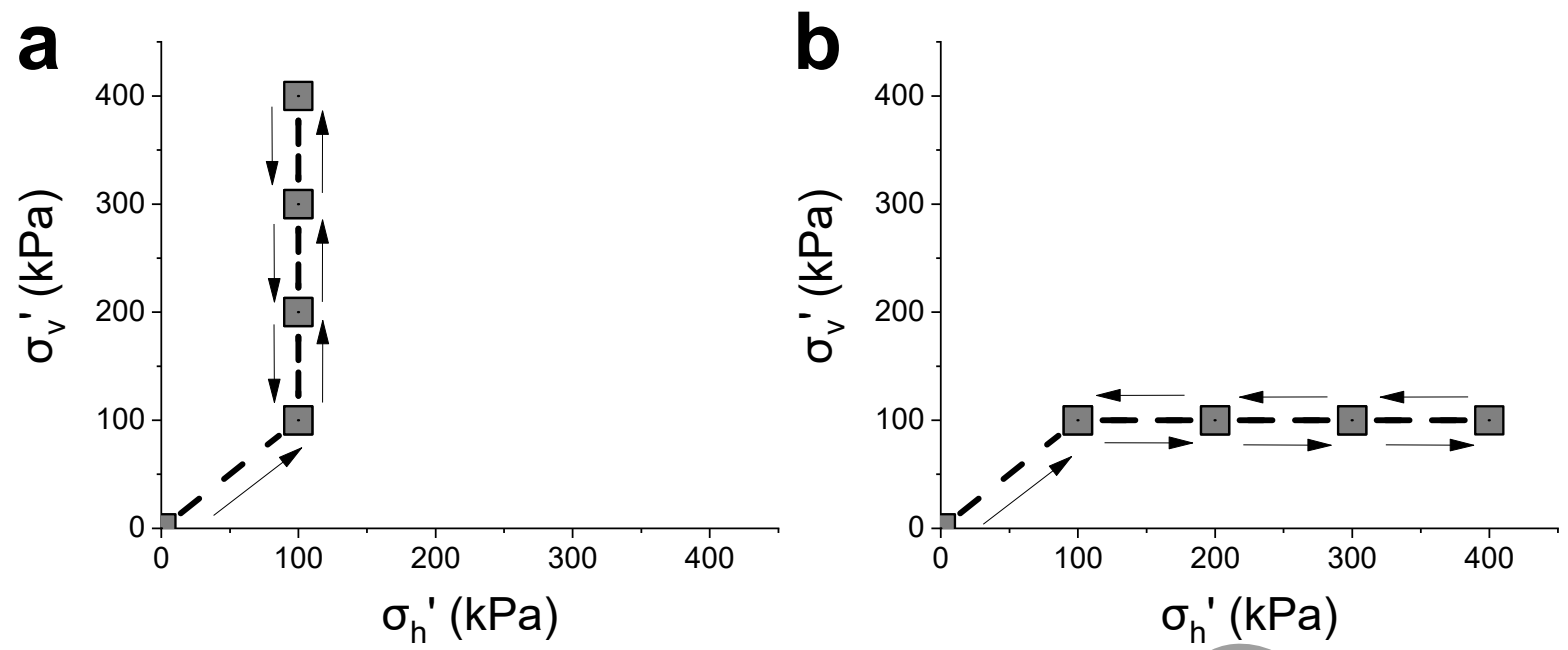

Figure 3. Stress path of the anisotropic consolidation tests: (a) $\sigma_{h}^{\prime}=100 \mathrm{kPa}$; (b) $\sigma_{\mathrm{v}}^{\prime}=100$ $\mathrm{kPa}$. 


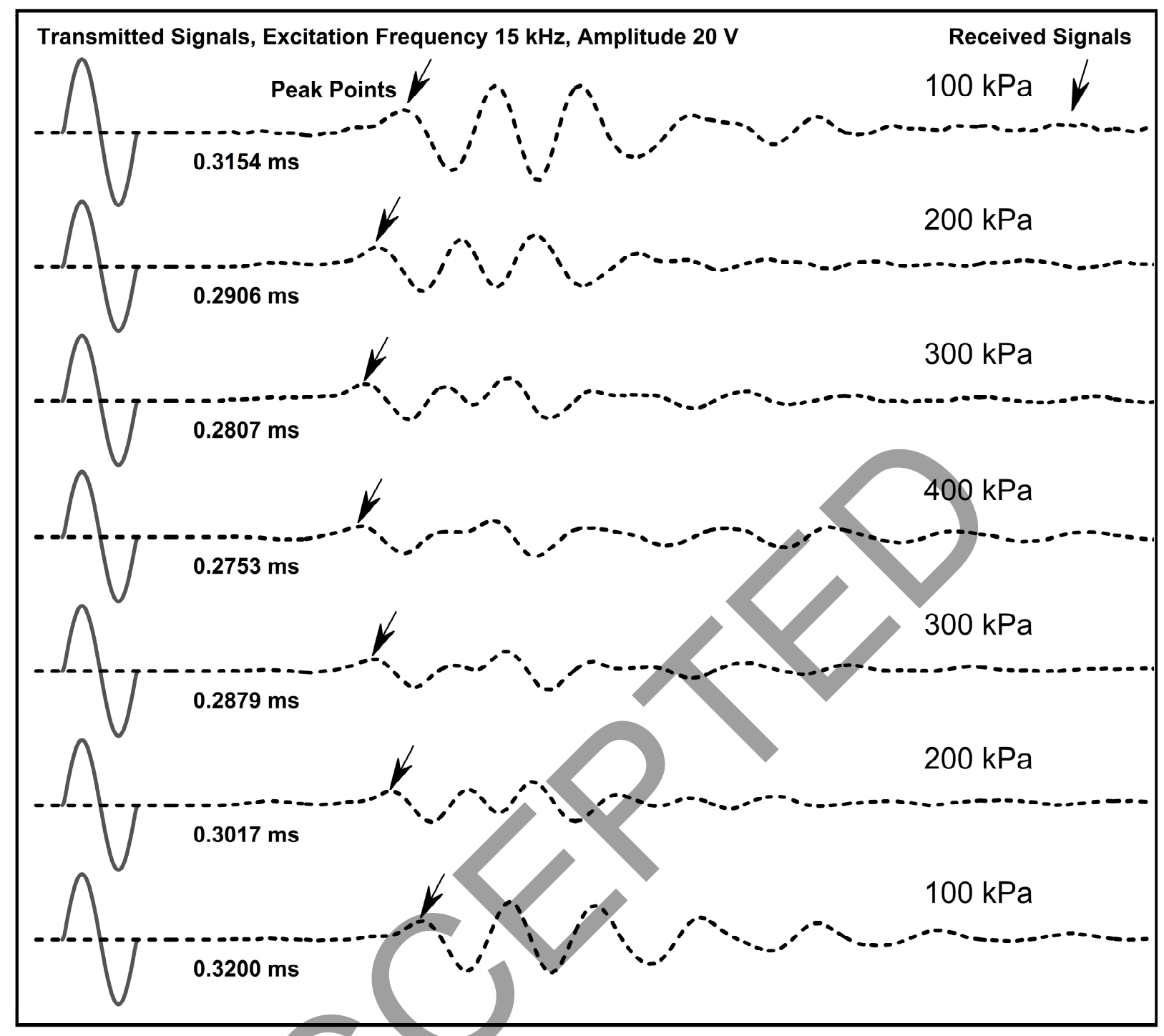

Time (ms)

Figure 4. Waveforms of shear wave under different effective stresses 

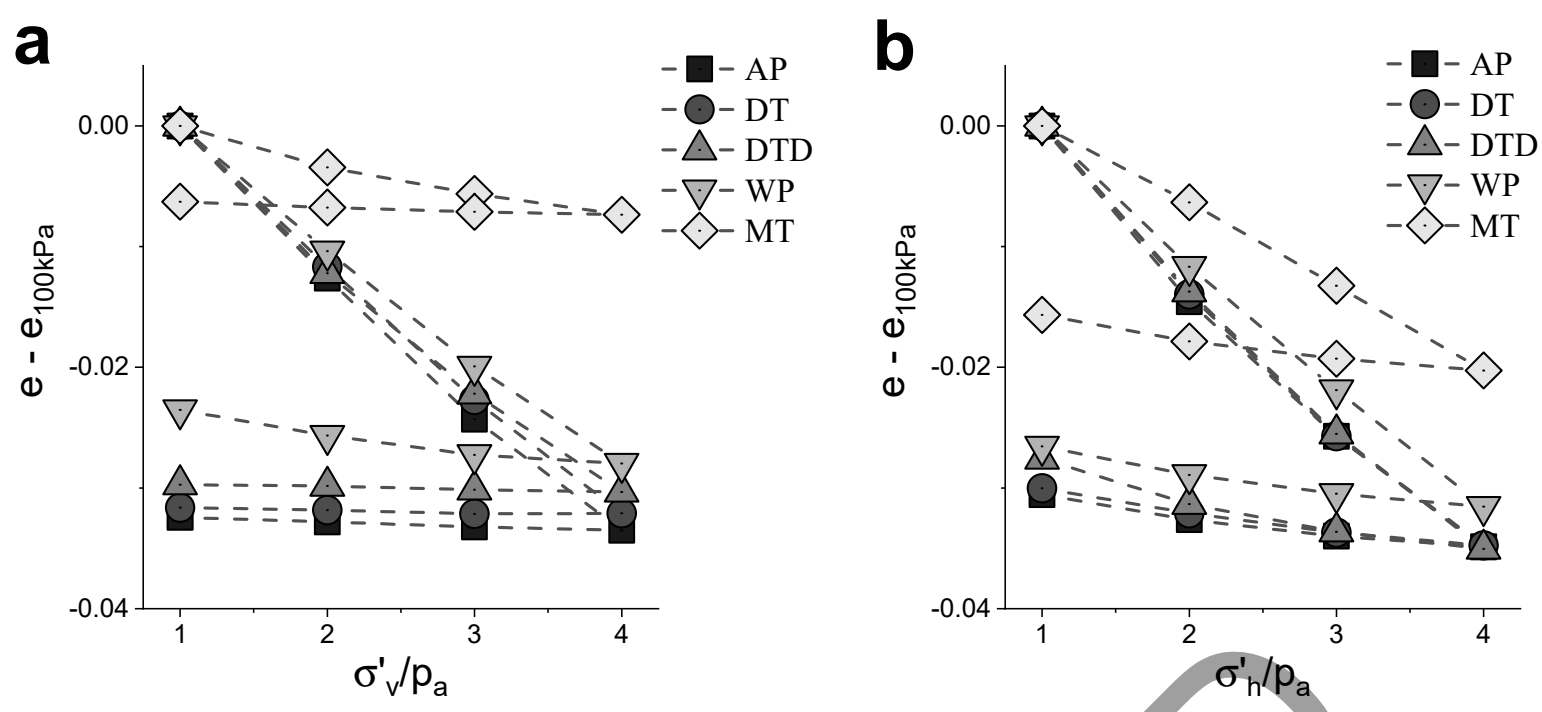

Figure 5. Void ratio variation versus the effective stress: (a) $\sigma_{h}^{\prime}=100 \mathrm{kPa}$; (b) $\sigma_{\mathrm{v}}^{\prime}=100$ $\mathrm{kPa}$. 

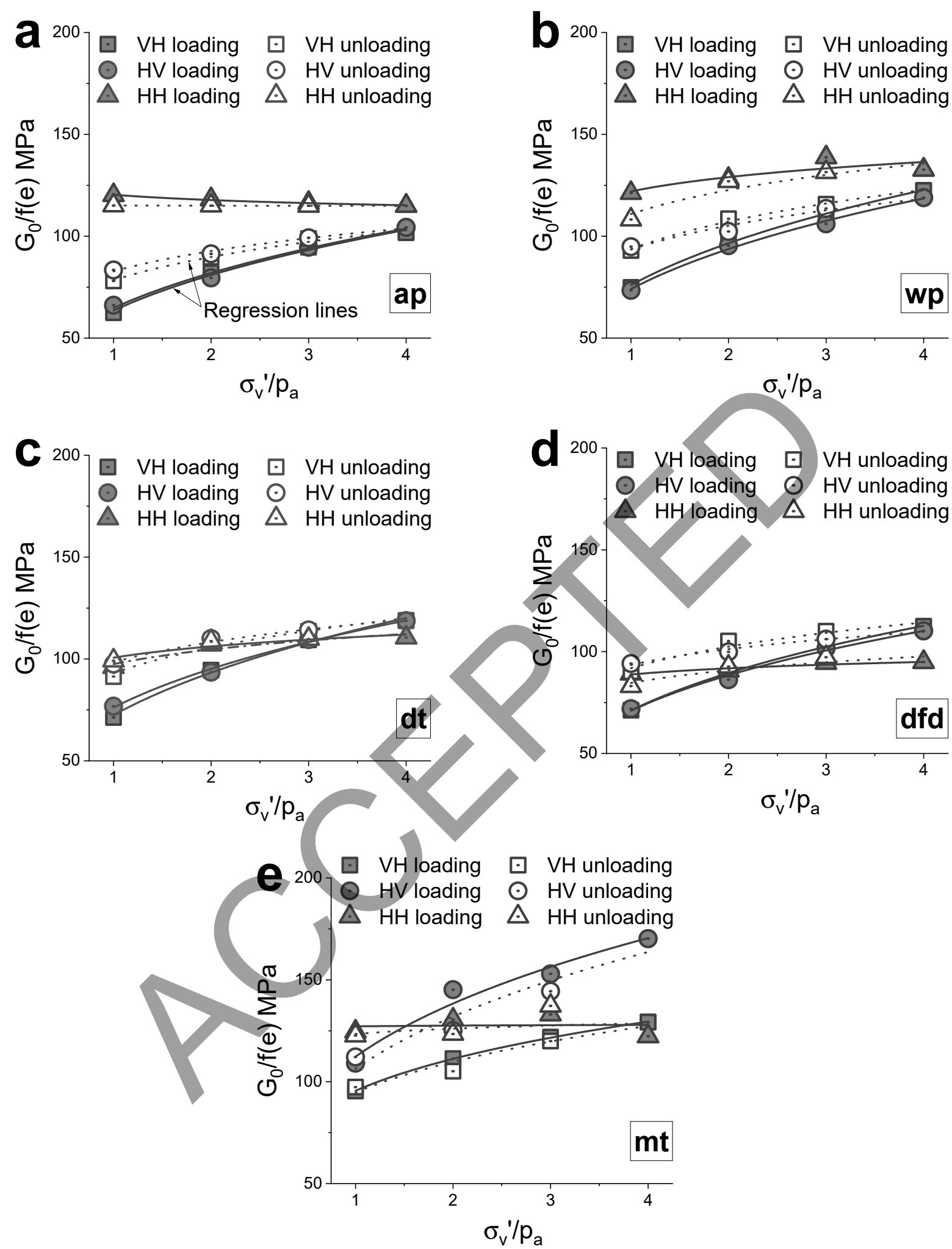

Figure 6. Normalized shear modulus versus the effective stress: (a) air pluviation; (b) water pluviation; (c) dry tamping; (d) dry funnel deposition; (e) moist tamping 

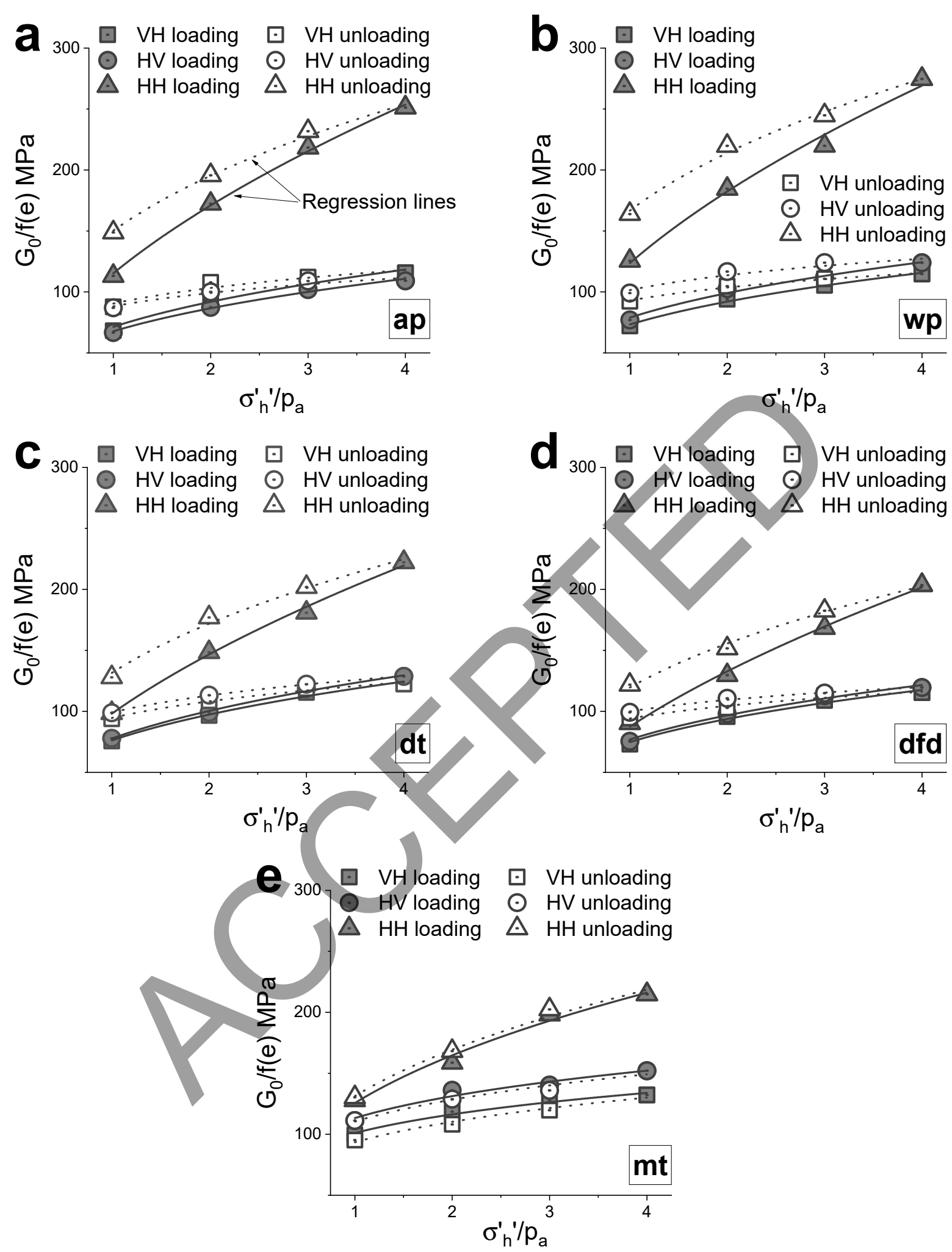

Figure 7. Normalized shear modulus versus the effective stress: (a) air pluviation; (b) water pluviation; (c) dry tamping; (d) dry funnel deposition; (e) moist tamping. 

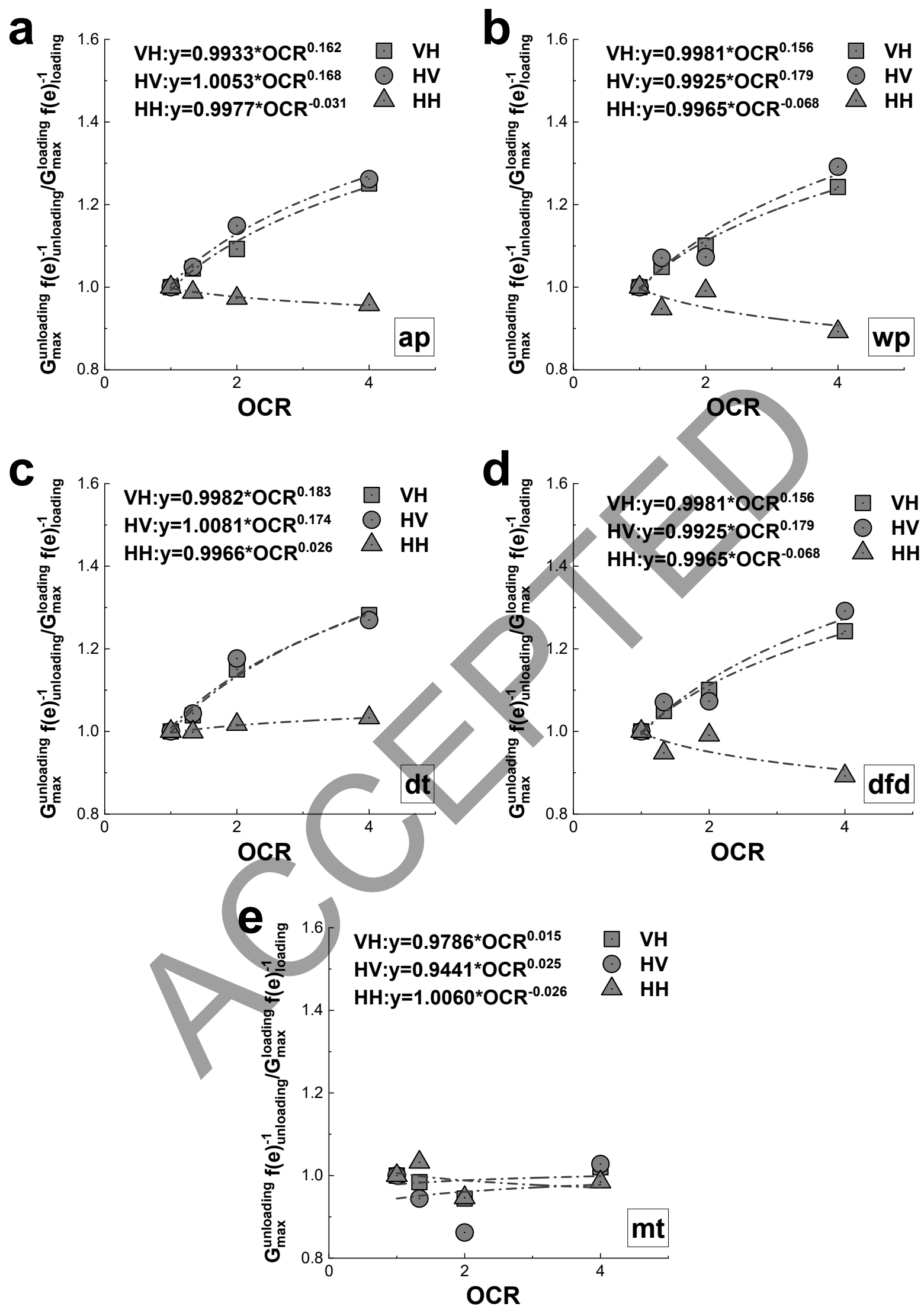

Figure 8. Ratio of the normalized shear modulus versus OCR for tests with $\sigma_{h}^{\prime}=100 \mathrm{kPa}$ (a) air pluviation; (b) water pluviation; (c) dry tamping; (d) dry funnel deposition; (e) moist tamping 

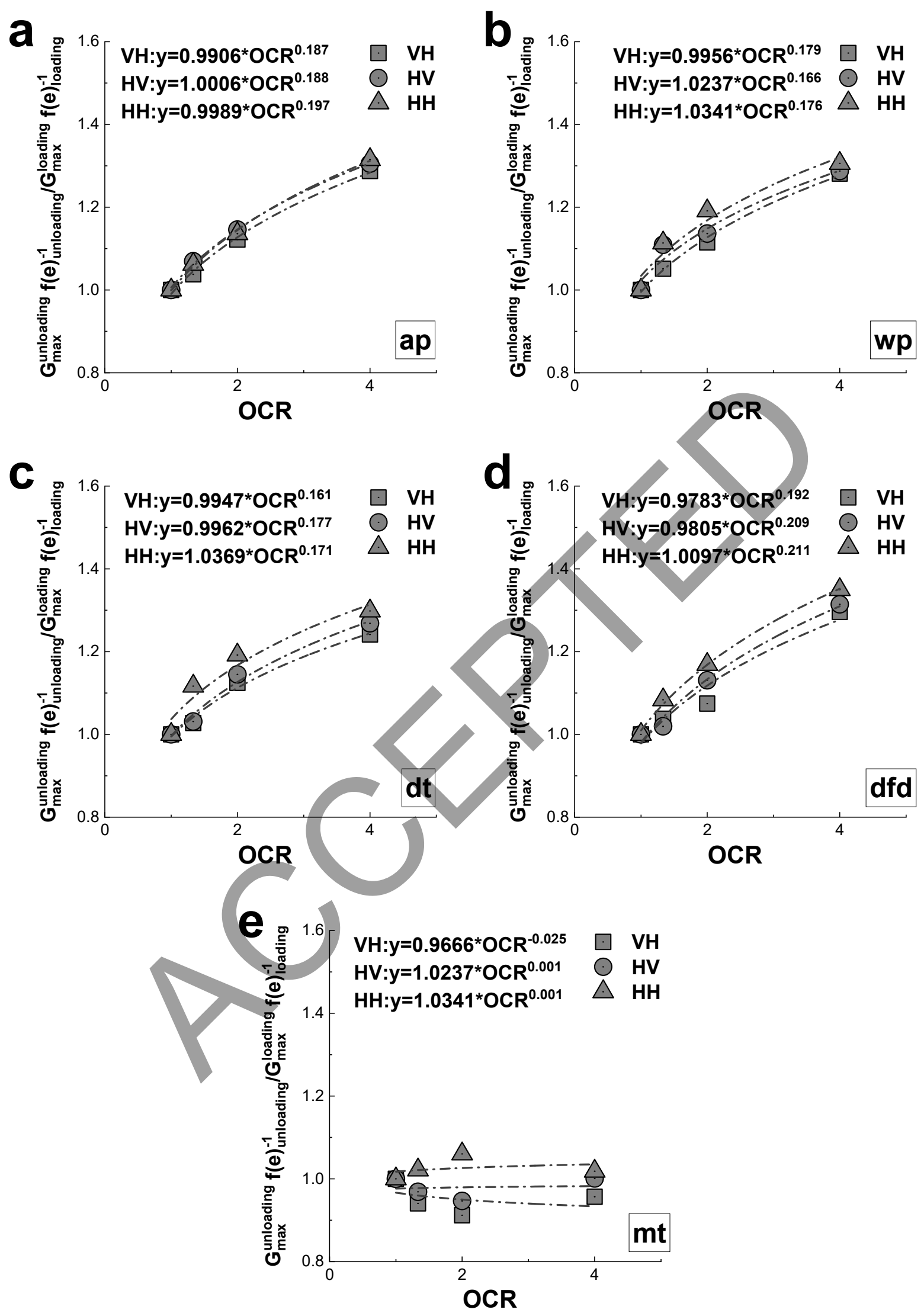

Figure 9. Ratio of the normalized shear modulus versus OCR for tests with $\sigma^{\prime}{ }_{v}=100 \mathrm{kPa}$ (a) air pluviation; (b) water pluviation; (c) dry tamping; (d) dry funnel deposition; (e) moist tamping. 

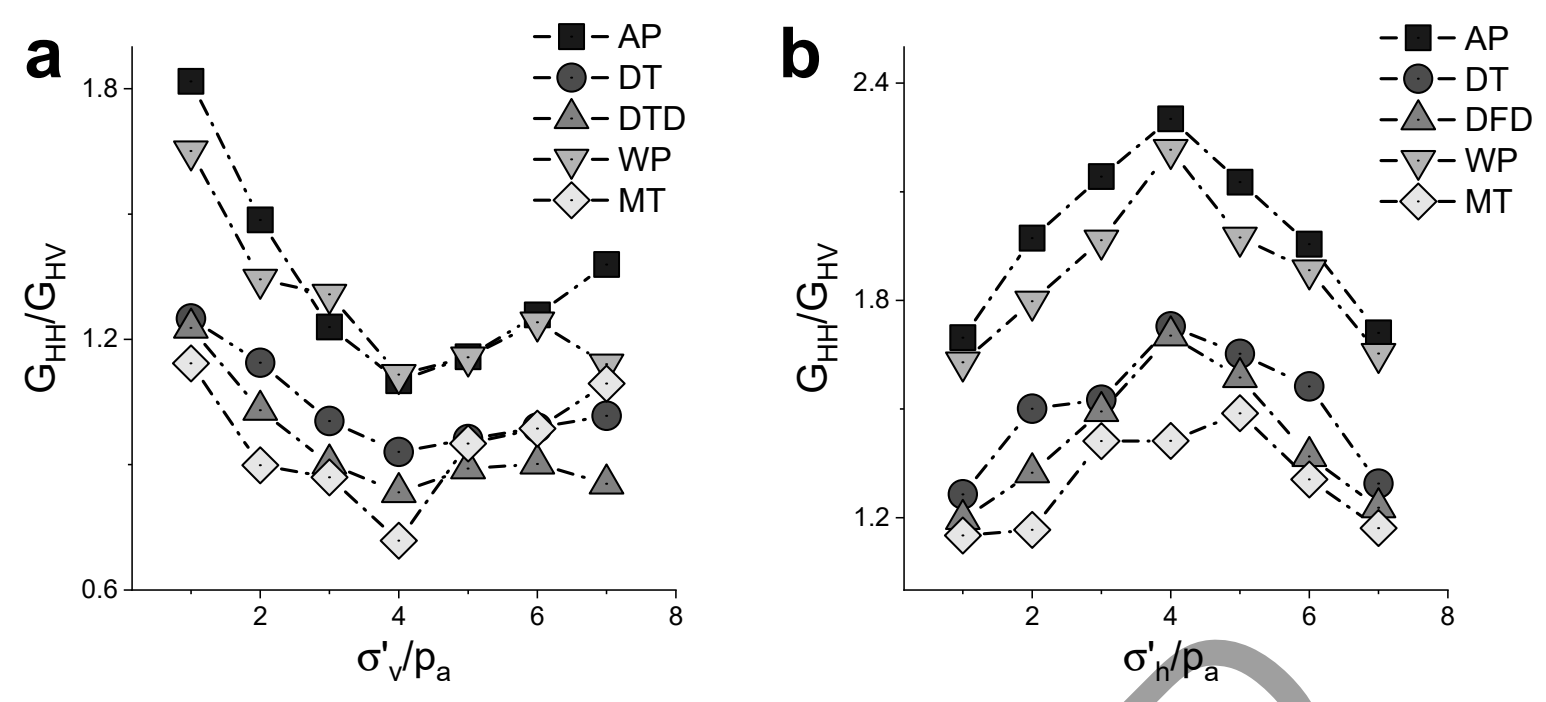

Figure 10. Variation of stiffness anisotropy versus the effective stress: (a) $\sigma_{h}^{\prime}=100 \mathrm{kPa}$; (b) $\sigma^{\prime}{ }_{\mathrm{v}}$ $=100 \mathrm{kPa}$. 